\title{
EDITORIAL
}

\section{What Price the Environmental Movement?}

lthough much has been written about what is commonly referred to as 'the environmental movement', we do
not know of a satisfactory definition for it and so go on thinking of it as the active expression of the natural human concern to work for a satisfactory environment of Man and Nature throughout the world. As such it is political in a desirably 'people-pushing' way that ignores other partisanship but lacks cohesion and even concerted direction.

Consequently we were less surprised than dismayed to hear a wise and eminent associate say very recently, on returning from the latest United Nations General Assembly, that the governments of leading countries seem to be losing interest in the environment - to the extent that some are even withholding funds which they had pledged in support of activities on its behalf. If this leads to privation and wider soul-searching and, thereafter, increased understanding and financial support to help counter further deterioration of important aspects of our environment, it will emulate the proverbial 'ill-wind' that ultimately brings some good. For the environment and, surely, concern for it in enlightened quarters, will not go away but remain with us to stay, while its further deterioration on various 'fronts' seems inevitable in view of the projected continuing build-up of human population-pressures.

As time goes on it is becoming increasingly conceivable that nuclear holocaust or widespread famine with disease may relieve these pressures to a horrific extent relatively soon rather than late, but of course without removing many of the foreseeable environmental ills. For the stark fact remains that population growth and concomitant development cannot continue indefinitely on our finite globe. Meanwhile people are becoming more and more unsettled and afraid for their own and the world's future, and, as a result, apprehensive and aggressive-hence, it seems to us, much of the growing unrest in the world which finds its extreme expression in the 'Beirut Syndrome' of people killing one another in increasing numbers for, often, no clear reason. Consequently governments are apt to think of other matters as more pressing than environmental concern.

Yet somehow the environmental movement must prevail, and so it was comforting to hear our wise colleague say that he believes it will indeed do so-even if it has to be mainly through the activities of dedicated individuals who will need to increase and ever-widen their efforts. In this context it is also comforting to think that when, in the middle 1960's, we 'saw the light' as to where the world was going environmentally, there was no such thing as a Ministry of Environment in any of the major governments of the world; in contrast they seemingly all have to have such a body now, whatever it may be called and, actually, do. Another source of comfort is that, nowadays, pollution from industry is coming more and more under control-to the extent that firms are said widely to have to spend from ten to fifteen per cent of their total budgets on satisfying environmental standards as required by often rigid laws in most enlightened countries. Yet another encouraging feature is the growth of environmental awareness in many quarters and connections practically throughout the world, as a result of which special journals are being founded--including one of that very name which we were privileged to encourage in India.

In the face of such advances, we ought not to have too much difficulty in surviving such backlash of commercial and other interests as may attempt to get 'ecologists' and conservationists branded as enemies of progress-especially in view of the demonstrable fact that environmentalists and developers can often work very well in unison and have both their interests flourish together. There can be no serious doubt that, in the long run, human welfare will be best served by concordant working of environmentalists and industrialists together, for the mutual benefit of their widely overlapping interests. Herein may lie one of the great hopes for much of Nature and the future world, the other being human intelligence.

In all these and other circumstances we ought not to worry if the hippies have given our venerable science of ecology a bad name (though in a much-changed sense). But whether or not as a result of such items, it is proving increasingly difficult to get even outstandingly prominent environmentalists adopted into such leading compilations as Who's Who in the World or The International Who's Who and, far more important, to obtain adequate finance for even the most urgent environmental needs (though we could put any willing sources in touch with worthy seekers at any time!). Meanwhile, regrettably, some of the few major awards (such as the Pahlavi and Tyler* ones) for which environmentalists were eligible have ceased or are in jeopardy, others being now greatly needed.

Most fortunately, among men and women of ability and dedication, money is only one of the other desiderata, and much can be done with very little of it. So it is gratifying to have been able to encourage the launching soon of two new international journals by enterprising groups that are interested in one case in environmental education and, in the other, in the basis of so many of the world's gravest problems, namely human population. ${ }^{\dagger}$ Another encouraging prospect is 'The World Decade of The Biosphere, 1982-92', fostered in our latest issue, which is being designed to bring home to people everywhere the concept of The Biosphere and mankind's utter dependence on it of which Homo sapiens constitutes an intergral but all-too-powerful part. As far as we are aware, each of these developments depends far more on goodwill than on any budget, and such is the case with our Journal and its owning Foundation and ancillary activities.

So despite its vast domain and importance, the environmental movement has no price and cannot be bought or sold - but could be much helped on its difficult though imperative way by proper financial support which seems to be its due as a potential world-saver.

N:P.

\footnotetext{
*Since this editorial went to press, we have heard from the former administrator of the Tyler Award that it is "being transferred to the University of Southern California' (George C. Bales, in litt. 25 February 1981) and hope to publish details in our next issue.

t Having been asked to name these new Journals, I think this may now be done with impunity: they are, respectively, The Environmentalist and Population Research and Policy Review.
} 